\title{
Demographic and Social Factors Associated with COVID-19 Vaccination Initiation Among Adults Aged $\geq 65$ Years - United States, December 14, 2020-April 10, 2021
}

\begin{abstract}
Ari Whiteman, $\mathrm{PhD}^{1,2}$; Alice Wang, $\mathrm{PhD}^{1}$; Kelly McCain, MSPH ${ }^{1,2}$; Betsy Gunnels, MSPH${ }^{1}$; Robin Toblin, $\mathrm{PhD}^{1}$; James Tseryuan Lee, MD ${ }^{1}$; Carolyn Bridges, MD ${ }^{1}$; Laura Reynolds, MPH ${ }^{1}$; Bhavini Patel Murthy, MD ${ }^{1}$; Judy Qualters, PhD ${ }^{1}$; James A. Singleton, PhD ${ }^{1}$; Kimberley Fox, $\mathrm{MD}^{1}$; Shannon Stokley, DrPH${ }^{1}$; LaTreace Harris, MPH ${ }^{1}$; Lynn Gibbs-Scharf, $\mathrm{MPH}^{1}$; Neetu Abad, PhD ${ }^{1}$; Kathryn A. Brookmeyer, PhD ${ }^{1}$; Susan Farrall, $\mathrm{MPH}^{1}$; Cassandra Pingali, MPH, MS ${ }^{1}$; Anita Patel, $\mathrm{MD}^{1}$; Ruth Link-Gelles, $\mathrm{PhD}^{1}$; Sharoda Dasgupta, PhD ${ }^{1}$; Radhika Gharpure, DVM ${ }^{1}$; Matthew D. Ritchey, DPT ${ }^{1}$; Kamil. E. Barbour, $\mathrm{PhD}^{1}$
\end{abstract}

\section{On May 11, 2021, this report was posted as an MMWR Early} Release on the MMWR website (https://www.cdc.gov/mmwr).

Compared with other age groups, older adults (defined here as persons aged $\geq 65$ years) are at higher risk for COVID-19associated morbidity and mortality and have therefore been prioritized for COVID-19 vaccination $(1,2)$. Ensuring access to vaccines for older adults has been a focus of federal, state, and local response efforts, and CDC has been monitoring vaccination coverage to identify and address disparities among subpopulations of older adults (2). Vaccine administration data submitted to CDC were analyzed to determine the prevalence of COVID-19 vaccination initiation among adults aged $\geq 65$ years by demographic characteristics and overall. Characteristics of counties with low vaccination initiation rates were quantified using indicators of social vulnerability data from the 2019 American Community Survey.* During December 14, 2020-April 10, 2021, nationwide, a total of $42,736,710(79.1 \%)$ older adults had initiated vaccination. The initiation rate was higher among men than among women and varied by state. On average, counties with low vaccination initiation rates $(<50 \%$ of older adults having received at least 1 vaccine dose), compared with those with high rates $(\geq 75 \%)$, had higher percentages of older adults without a computer, living in poverty, without Internet access, and living alone. CDC, state, and local jurisdictions in partnerships with communities should continue to identify and implement strategies to improve access to COVID-19 vaccination for older adults, such as assistance with scheduling vaccination appointments and transportation to vaccination sites, or vaccination at home if needed for persons who are homebound. ${ }^{\dagger}$ Monitoring demographic and social factors affecting COVID-19 vaccine access for older adults and prioritizing efforts to ensure equitable access to COVID-19 vaccine are needed to ensure high coverage among this group.

\footnotetext{
*https://www.census.gov/programs-surveys/acs

$\dagger^{\dagger}$ https://www.cdc.gov/vaccines/covid-19/clinical-considerations/homeboundpersons.html; https://www.cdc.gov/vaccines/covid-19/clinical-considerations/ older-adults-and-disability/access.html
}

COVID-19 vaccine administration data are reported to CDC by multiple entities using immunization information systems, the Vaccine Administration Management System, pharmacy systems, or direct submission of electronic health records. ${ }^{\S}$ Vaccination initiation rates were estimated as the percentage of older adult residents who received at least 1 dose of COVID-19 vaccine during December 14, 2020-April 10, 2021, and whose data were reported to CDC by April 16, 2021.9 Vaccination initiation rates by age group (65-74 or $\geq 75$ years) and sex, nationally and by state, ${ }^{* *}$ were estimated by dividing demographic data reported for each vaccine recipient by population estimates for adults aged $\geq 65$ years from the U.S. Census Bureau 2019 Population Estimates Program. ${ }^{\dagger \dagger}$ Analyses of vaccination initiation rates by race/ethnicity of the vaccine recipient were conducted at the national level only (because of a high level of missing data by state and low sample size for some race/ethnicity groups) and are presented as the percentage of total adults aged $\geq 65$ years with known race/ ethnicity information in each race/ethnicity category.

\footnotetext{
$\$$ https://www.cdc.gov/vaccines/covid-19/vaccination-provider-support.html; https://www.cdc.gov/vaccines/covid-19/reporting/vams/index.html

5 Providers are required to report administration records to the state immunization information system within 72 hours; 5 additional days of observation were included to account for delays in reporting and transmission of records to CDC. Data include all COVID-19 vaccine manufacturers, including the Janssen (Johnson \& Johnson) vaccine, which only requires a single dose.

** Exclusions from the state-level dataset include 1) recipients for whom state of residence was unknown $(48,524) ; 2)$ recipients aged $\geq 65$ years for whom specific age $(36,153)$ or sex $(318,018)$ was unknown; and 3$)$ residents of eight U.S. territories and freely associated states and armed forces overseas $(409,206)$ for which population denominator data were not available.

$\dagger \dagger$ Exclusions from the county-level dataset include 1) recipients for whom county of residence was unknown $(2,406,423)$ or was known yet reported with an invalid state of residence $(70,955) ; 2)$ recipients for whom state of residence was unknown $(28,313) ; 3)$ residents of eight U.S. territories, freely associated states, and armed forces overseas $(405,139)$ for which population denominator data were not available, and after excluding based on the above criteria; 4) residents of Delaware and the District of Columbia because each has three or fewer counties $(218,240)$; and 5) residents of Georgia, Hawaii, South Dakota, and West Virginia because of unknown county of residence in $>20 \%$ of records $(776,207)$.
} 
For county-level analyses, five frequent indicators of social vulnerability $(3,4)$ for older adults were gathered from the U.S. Census Bureau American Community Survey 5-year estimates from 2019: the percentage of older adult county residents 1) without a computer (e.g., desktop or laptop computer [excludes mobile phones]); 2) with a computer but without Internet access; 3) living alone; 4) having an annual income below the federal poverty level; and 5) identifying as a person with race/ethnicity other than non-Hispanic White (White) alone. A generalized estimating equation for each of these social vulnerability indicators was used with a normal distribution and identity link function to quantify and compare the average percentage of older adults with social vulnerabilities in each county to the county vaccination initiation rate, divided into initiation categories of $<50 \%, 50 \%$ to $<75 \%$, and $\geq 75 \%$. $\$ \$ S$ SAS software (version 9.4; SAS Institute) was used to conduct analyses. This activity was reviewed by CDC and was conducted consistent with applicable federal law and CDC policy. 99

During December 14, 2020-April 10, 2021, a total of $42,736,710$ older adult residents of 50 states and the District of Columbia received at least 1 dose of COVID-19 vaccine (Table). The rate of vaccination initiation was $79.1 \%$ overall and, by jurisdiction, ranged from $68.9 \%$ (Alabama) to $99.9 \%$ (New Hampshire). Nationally, the rate of vaccination initiation was 1.3 percentage points higher among persons aged $65-74$ years $(79.6 \%)$ than among persons aged $\geq 75$ years $(78.3 \%)$. Among persons aged $65-74$ years, vaccination initiation rates ranged from $66.8 \%$ (Alabama) to $99.9 \%$ (New Hampshire), and among persons aged $\geq 75$ years, ranged from $69.1 \%$ (Mississippi) to 99.9\% (New Hampshire) (Figure 1). Nationally, the vaccination initiation rate was 2.1 percentage points higher among men $(79.6 \%)$ than among women $(77.5 \%)$. $^{* * *}$

Among recipients of at least 1 dose of COVID-19 vaccine, race/ethnicity was missing in $17,903,625$ (41.9\%) records. Among the 24,833,085 recipients with reported race/ethnicity, 17,561,065 (70.7\%) were White; 1,885,433 (7.6\%) were non-Hispanic Black; 1,548,776 (6.2\%) were non-Hispanic multiracial; 1,657,517 (6.7\%) were Hispanic; 880,040 (3.5\%) were non-Hispanic Asian; 190,856 (0.8\%) were non-Hispanic American Indian or Alaskan Native; 42,747 (0.2\%) were Native Hawaiian or Other Pacific Islander; and 1,066,651 (4.3\%) identified as "all other races/ethnicities."

Counties with $<50 \%$ vaccination initiation rates had significantly higher average percentages of older adults with social

\footnotetext{
$\$ \$$ https://www.census.gov/data/datasets/time-series/demo/popest/2010scounties-total.html

9945 C.F.R. part 46, 21 C.F.R. part 56; 42 U.S.C. Sect. 241(d); 5 U.S.C. Sect. 552a; 44 U.S.C. Sect. 3501 et seq.

*** Among recipients aged $\geq 65$ years, sex was missing in 318,018 of records.
}

vulnerabilities than did counties with vaccination initiation rates $\geq 75 \%$, with the exception of the race/ethnicity other than White indicator (Figure 2 ). In counties with $<50 \%$ vaccination initiation rates, an average of $24.6 \%$ (95\% confidence interval $[\mathrm{CI}]=22.3 \%-26.9 \%)$ of older adults did not have a computer, compared with $19.1 \%(95 \% \mathrm{CI}=17.8 \%-20.4 \%)$ in counties with $\geq 75 \%$ vaccination initiation rates. Similarly, the average percentage of older adults without Internet access was $9.9 \%$ $(95 \% \mathrm{CI}=8.9 \%-10.9 \%)$ in counties with $<50 \%$ vaccination initiation rates, compared with $7.4 \%(95 \% \mathrm{CI}=7.0 \%-7.8 \%)$ in counties with $\geq 75 \%$ vaccination initiation rates. The average percentage of older adults living in poverty was $10.3 \%$ $(95 \% \mathrm{CI}=9.2 \%-11.4 \%)$ in counties with $<50 \%$ vaccination initiation rates, compared with $7.6 \%(95 \% \mathrm{CI}=7.0 \%-8.2 \%)$ in counties with $\geq 75 \%$ vaccination initiation rates. The average percentage of older adults living alone was 14.3\% (95\% $\mathrm{CI}=13.8 \%-14.9 \%)$ in counties with $<50 \%$ vaccination initiation rates, compared with $12.2 \%(95 \% \mathrm{CI}=11.8 \%-12.6 \%)$ in counties with $\geq 75 \%$ vaccination initiation rates. The average percentage of older adults indicating race/ethnicity other than White was similar in counties with $<50 \%$ vaccination initiation rates $(8.0 \% ; 95 \% \mathrm{CI}=4.9 \%-11.1 \%)$ and $\geq 75 \%$ vaccination initiation rates $(9.3 \%$; $95 \% \mathrm{CI}=6.4 \%-12.1 \%)$.

\section{Discussion}

Among adults aged $\geq 65$ years in the United States, $79.1 \%$ had initiated COVID-19 vaccination as of April 10, 2021. Despite COVID-19 vaccine becoming available on December 14, 2020, and many states including older adults among the first groups eligible for vaccination, as many as 11.3 million older adults remained unvaccinated as of April 10,2021. ${ }^{\dagger \dagger}$ Further, vaccination initiation was lower among certain demographic groups (e.g., women) and states, and on average, counties with lower vaccination initiation rates had higher percentages of older adults with social vulnerabilities.

As of April 10,2021, vaccination initiation rates among older adults nationwide were higher among men and persons aged $65-74$ years than among women and persons aged $\geq 75$ years. In comparison, according to reports of recent estimates, no differences by sex have been observed in initiation of vaccination with influenza and shingles vaccine, both of which are also recommended for older adults. $\$ \$ \$$ Vaccination acceptance by age group and sex will be followed to determine whether these differences persist as vaccine availability expands.

\footnotetext{
i†† The U.S. Census Bureau estimates the population of older adults to be $54,058,263$. With $42,736,710$ older adults receiving $\geq 1$ COVID-19 vaccine dose, an estimated 11,321,553 older adults remained unvaccinated as of April 10, 2021.

$\$ \$ \$$ https://www.cdc.gov/nchs/products/databriefs/db370.htm; https://www. cdc.gov/flu/fluvaxview/coverage-1920estimates.htm
} 
TABLE. COVID-19 vaccination initiation rate among adults aged $\geq 65$ years, by state, age group, and sex* — United States, December $14,2020-$ April 10, 2021

\begin{tabular}{|c|c|c|c|c|c|}
\hline \multirow[b]{3}{*}{ Jurisdiction } & \multicolumn{5}{|c|}{ No. of persons with at least 1 COVID-19 vaccine dose (\% vaccination initiation) } \\
\hline & \multirow{2}{*}{$\begin{array}{l}\text { Total men and women } \\
\text { aged } \geq 65 \text { years }\end{array}$} & \multicolumn{2}{|c|}{ Age group, yrs } & \multicolumn{2}{|c|}{ Sex } \\
\hline & & $65-74$ & $\geq 75$ & Men & Women \\
\hline National total & $42,736,710(79.1)$ & $25,051,017(79.6)$ & $17,685,693(78.3)$ & $19,166,329(79.6)$ & $23,252,363(77.5)$ \\
\hline Alabama & $585,732(68.9)$ & $334,760(66.8)$ & $250,972(72.0)$ & $260,221(70.1)$ & $324,554(67.8)$ \\
\hline Alaska & $70,003(76.4)$ & $47,306(77.2)$ & $22,697(74.9)$ & 34,965 (76.9) & $34,306(74.4)$ \\
\hline Arizona & $991,737(75.8)$ & $568,864(75.7)$ & 422,873 (75.9) & $460,031(76.4)$ & $528,908(74.9)$ \\
\hline Arkansas & $372,077(71.0)$ & $210,948(69.7)$ & $161,129(72.9)$ & $165,732(71.0)$ & $200,562(69.1)$ \\
\hline California & $4,939,416(84.6)$ & $2,934,905(86.7)$ & $2,004,511(81.8)$ & $2,228,999(85.7)$ & $2,690,716(83.2)$ \\
\hline Colorado & $677,637(80.4)$ & 415,844 (79.6) & 261,793 (81.7) & $312,828(80.9)$ & $363,544(79.8)$ \\
\hline Connecticut & $549,241(87.1)$ & $308,545(87.5)$ & $240,696(86.8)$ & $242,538(87.9)$ & $305,959(86.4)$ \\
\hline Delaware & $159,934(84.7)$ & $96,468(85.5)$ & $63,466(83.5)$ & $71,975(85.1)$ & $87,258(83.6)$ \\
\hline District of Columbia & $65,115(74.6)$ & $39,254(78.2)$ & $25,861(69.7)$ & $27,615(77.3)$ & $37,141(72.0)$ \\
\hline Florida & $3,632,615(80.8)$ & $2,037,253(82.6)$ & $1,595,362(78.5)$ & $1,657,775(81.7)$ & $1,957,688$ (79.3) \\
\hline Georgia & $1,114,150(73.4)$ & $679,273(73.4)$ & 434,877 (73.6) & $483,369(73.1)$ & $608,901(71.2)$ \\
\hline Hawaii & $208,887(77.8)$ & 115,405 (75.9) & $93,482(80.3)$ & $96,534(79.4)$ & 110,985 (75.6) \\
\hline Idaho & $216,332(74.4)$ & $127,441(72.5)$ & $88,891(77.4)$ & $101,554(73.7)$ & 112,489 (73.6) \\
\hline Illinois & $1,641,523(80.3)$ & $955,599(81.3)$ & $685,924(79.1)$ & $726,643(81.2)$ & $908,243(79.1)$ \\
\hline Indiana & $822,469(75.8)$ & $481,217(75.6)$ & $341,252(76.0)$ & $370,554(77.1)$ & $450,399(74.4)$ \\
\hline lowa & $458,859(83.0)$ & $260,017(83.5)$ & $198,842(82.3)$ & $204,719(82.3)$ & $248,043(81.5)$ \\
\hline Kansas & $408,580(85.9)$ & $234,751(86.2)$ & $173,829(85.5)$ & $183,897(86.0)$ & $223,731(85.5)$ \\
\hline Kentucky & $583,439(77.7)$ & $349,547(78.0)$ & $233,892(77.3)$ & $262,481(78.8)$ & $318,951(76.4)$ \\
\hline Louisiana & $539,780(72.8)$ & $323,992(73.2)$ & $215,788(72.3)$ & $241,328(74.1)$ & $297,074(71.5)$ \\
\hline Maine & $252,223(88.4)$ & $150,338(88.9)$ & $101,885(87.7)$ & $116,099(89.3)$ & $135,291(87.1)$ \\
\hline Maryland & $771,161(80.4)$ & $452,878(80.6)$ & $318,283(80.0)$ & $337,410(81.3)$ & $429,662(78.9)$ \\
\hline Massachusetts & $1,025,207(87.7)$ & $588,874(87.5)$ & $436,333(88.0)$ & $445,646(87.6)$ & $570,880(86.4)$ \\
\hline Michigan & $1,333,607(75.5)$ & $787,506(75.9)$ & $546,101(75.0)$ & $606,985(76.7)$ & 725,509 (74.5) \\
\hline Minnesota & $784,098(85.2)$ & $452,519(85.2)$ & $331,579(85.2)$ & $357,349(85.2)$ & $419,766(83.8)$ \\
\hline Mississippi & $337,396(69.3)$ & $200,815(69.5)$ & $136,581(69.1)$ & $149,898(70.7)$ & $186,511(67.9)$ \\
\hline Missouri & 777,239 (73.2) & $446,746(73.2)$ & $330,493(73.1)$ & $349,730(74.4)$ & $426,141(72.0)$ \\
\hline Montana & $156,168(75.6)$ & $92,439(74.2)$ & 63,729 (77.9) & 74,335 (75.1) & $80,694(75.1)$ \\
\hline Nebraska & $255,621(81.8)$ & $146,664(82.0)$ & $108,957(81.6)$ & $115,091(81.7)$ & $137,046(79.9)$ \\
\hline Nevada & 366,508 (73.9) & $221,813(73.1)$ & $144,695(75.1)$ & $173,614(74.3)$ & $192,185(73.2)$ \\
\hline New Hampshire & 275,371 (99.9) & $168,361(99.9)$ & $107,010(99.9)$ & $124,620(99.9)$ & 144,939 (99.9) \\
\hline New Jersey & $1,178,070(79.8)$ & $678,214(81.4)$ & $499,856(77.8)$ & $513,465(80.5)$ & $659,877(78.8)$ \\
\hline New Mexico & $311,667(82.5)$ & $183,263(81.6)$ & $128,404(83.9)$ & $142,292(82.6)$ & $168,281(81.9)$ \\
\hline New York & $2,424,208(73.5)$ & $1,416,044(76.1)$ & $1,008,164(70.2)$ & $1,063,736(74.8)$ & $1,329,168(71.0)$ \\
\hline North Carolina & $1,308,317(74.7)$ & $785,219(75.0)$ & $523,098(74.2)$ & $580,067(75.7)$ & $717,019(72.8)$ \\
\hline North Dakota & $95,434(79.6)$ & $53,736(80.6)$ & $41,698(78.4)$ & $43,160(78.0)$ & $49,043(76.0)$ \\
\hline Ohio & $1,561,494(76.3)$ & 907,395 (76.3) & $654,099(76.3)$ & $686,703(76.1)$ & $849,450(74.2)$ \\
\hline Oklahoma & 494,734 (77.9) & $288,388(78.4)$ & $206,346(77.3)$ & $223,789(78.8)$ & $270,043(76.9)$ \\
\hline Oregon & $588,122(76.8)$ & $349,384(75.2)$ & $238,738(79.2)$ & $269,639(76.8)$ & 316,839 (76.4) \\
\hline Pennsylvania & $2,084,215(87.1)$ & $1,208,999$ (89.3) & $875,216(84.2)$ & $900,086(85.6)$ & $1,131,953(84.4)$ \\
\hline Rhode Island & $164,945(88.2)$ & $95,963(90.4)$ & $68,982(85.3)$ & 72,707 (89.3) & 91,967 (87.0) \\
\hline South Carolina & $726,525(77.5)$ & $432,172(75.7)$ & $294,353(80.3)$ & $327,860(78.7)$ & $397,494(76.4)$ \\
\hline South Dakota & 131,960 (86.9) & 74,675 (83.7) & $57,285(91.4)$ & $59,261(83.9)$ & $69,307(85.3)$ \\
\hline Tennessee & $806,104(70.5)$ & $465,412(68.3)$ & $340,692(73.7)$ & 362,397 (71.6) & $441,628(69.3)$ \\
\hline Texas & $2,801,138(75.0)$ & $1,694,786(75.5)$ & $1,106,352(74.3)$ & $1,250,589(74.9)$ & $1,519,330(73.6)$ \\
\hline Utah & $297,419(81.3)$ & $176,259(80.3)$ & $121,160(82.8)$ & $137,974(80.9)$ & $155,667(79.7)$ \\
\hline Vermont & $116,107(92.9)$ & $69,807(92.8)$ & $46,300(92.9)$ & $54,190(94.1)$ & 61,845 (91.7) \\
\hline Virginia & $1,089,519(80.2)$ & $642,006(80.0)$ & $447,513(80.4)$ & $489,594(81.2)$ & $597,041(79.0)$ \\
\hline Washington & $1,002,812(82.9)$ & $604,837(82.2)$ & 397,975 (83.9) & $458,165(83.0)$ & $537,814(81.8)$ \\
\hline West Virginia & $253,825(69.2)$ & $148,838(68.5)$ & $104,987(70.1)$ & $117,940(70.5)$ & $134,669(67.5)$ \\
\hline Wisconsin & $857,203(84.3)$ & $502,468(84.5)$ & $354,735(84.0)$ & $393,780(84.6)$ & $459,800(83.3)$ \\
\hline Wyoming & $70,767(71.4)$ & $42,810(70.7)$ & $27,957(72.4)$ & $34,400(72.0)$ & $36,052(70.1)$ \\
\hline
\end{tabular}

\footnotetext{
* Information on sex was missing for 318,018 (0.74\%) vaccine recipients.
} 

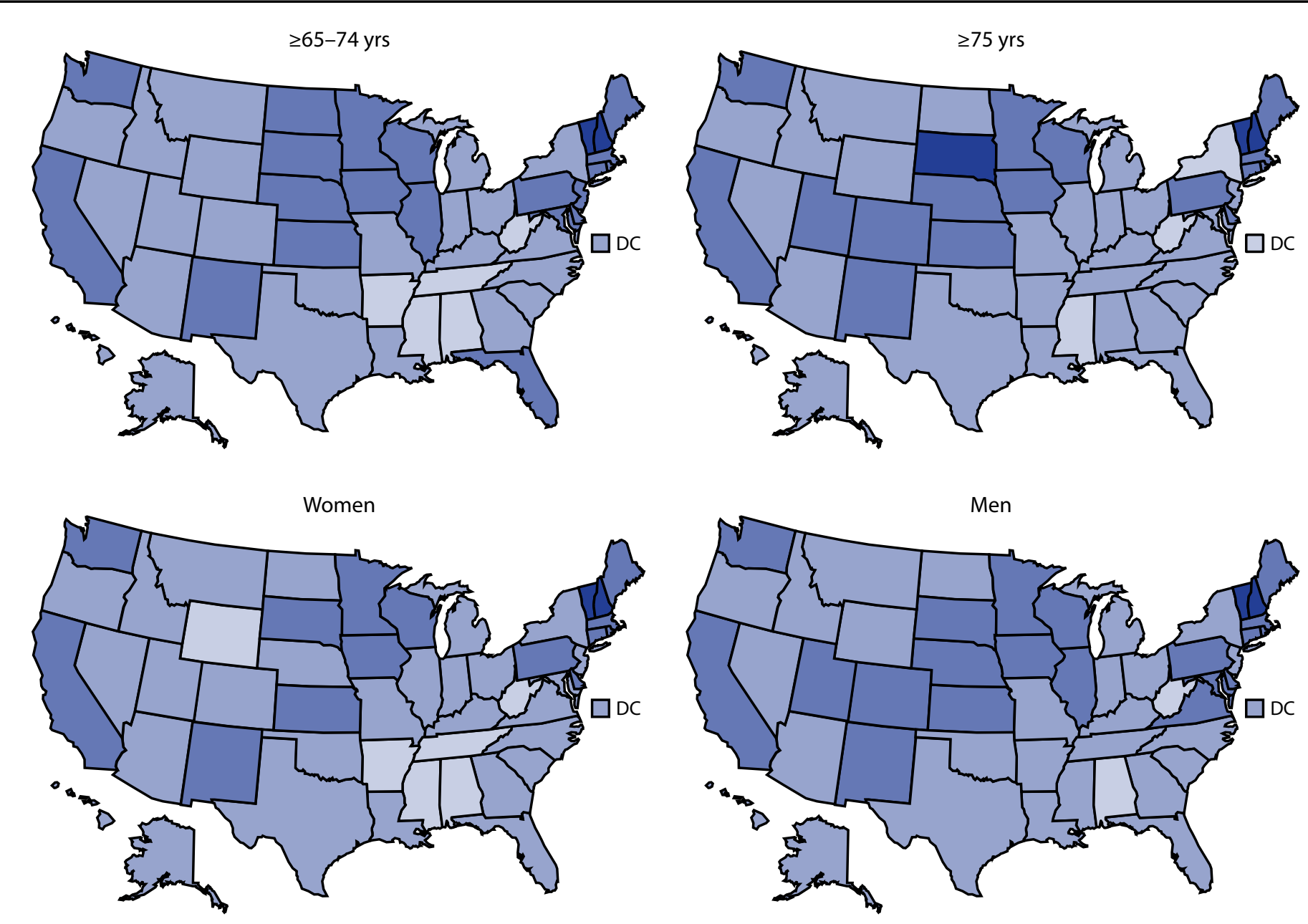

$61 \%-70 \%$

$71 \%-80 \%$

$81 \%-90 \%$

$91 \%-100 \%$

Abbreviation: $\mathrm{DC}=$ District of Columbia

Initiation overall and by demographic subpopulation varied by state, indicating that national-level analyses might obscure more local trends. New Hampshire and Vermont had the two highest overall vaccination initiation rates among older adults. New Hampshire established early partnerships with pharmacies, first responders, and the National Guard, in addition to creating a centralized state website for vaccination sign-up. In Vermont, state health authorities established a partnership to coordinate vaccine distribution and administration with the Association of Hospitals and Health Systems, which represents Vermont's 14 nonprofit hospitals. At the county level, the upper Midwest (e.g., Iowa, Minnesota, and Wisconsin) reported high vaccination initiation rates as well, relative to other regions.

In addition to differences in vaccination initiation rates by age group and sex identified at the state level, counties with $<50 \%$ initiation rates, on average, included higher percentages of older adults experiencing social vulnerabilities than did counties with $\geq 75 \%$ initiation. The identification of higher prevalence of older adults with social vulnerabilities in counties with low relative vaccination initiation rates is consistent with previous disparities identified among older adults who had received the shingles vaccine and among all adults who 
FIGURE 2. County residents aged $\geq 65$ years with selected indicators of social vulnerability, by vaccination initiation percentage - United States, December 14, 2020-April 10, 2021*

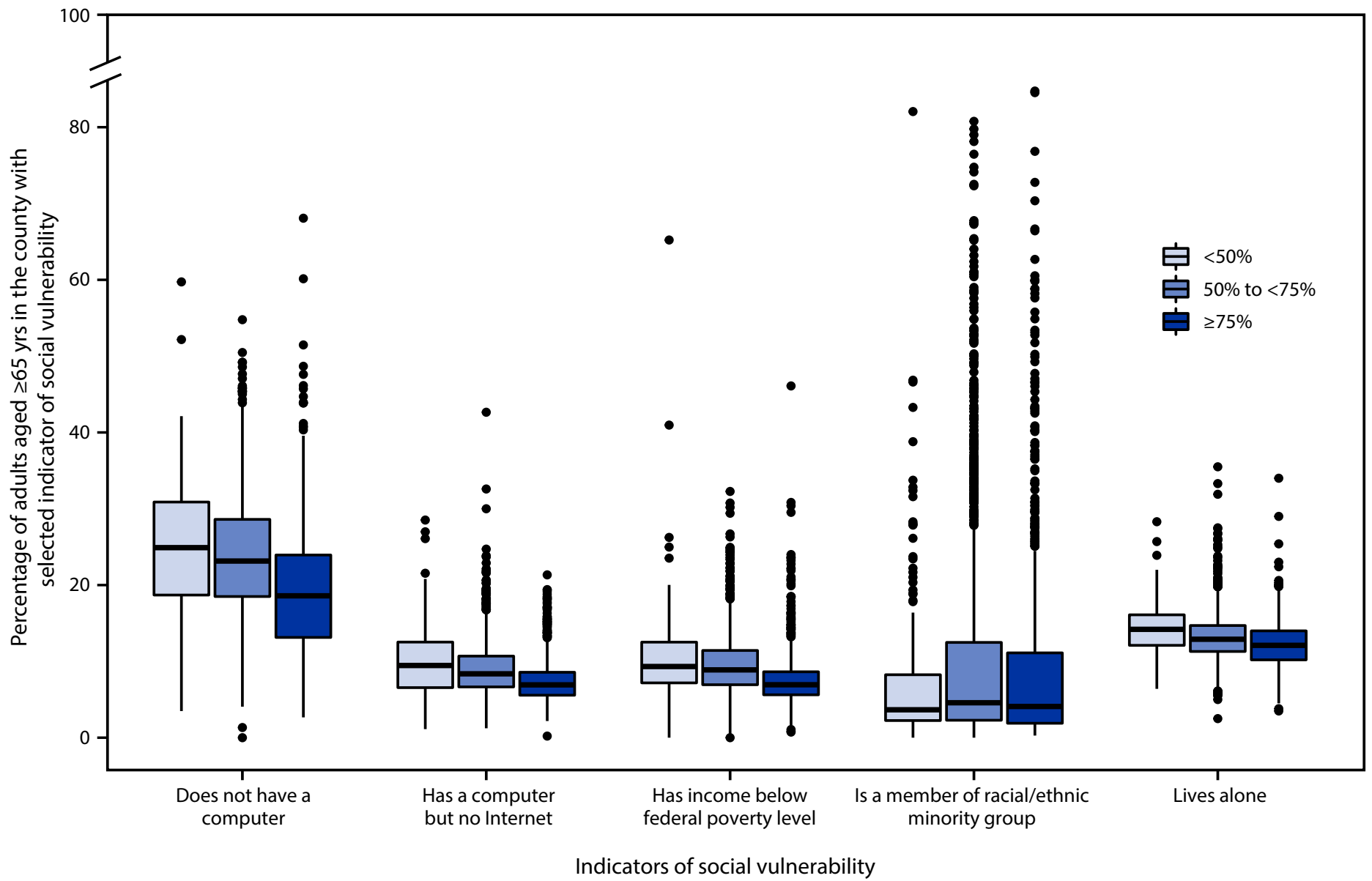

Abbreviation: $\mathrm{IQR}=$ interquartile range.

* This figure presents boxplots with the distributions of each indicator of social vulnerability for each of the categories of vaccination initiation among the population aged $\geq 65$ years. The horizontal line in each box indicates the median; the top and bottom edges of each box indicate the 75th and 25 th percentile values, respectively; the top and bottom of each vertical line show the maximum ( 75 th percentile value $+1.5 \times \mathrm{IQR}$ ) and minimum ( 25 th percentile value $-1.5 \times 1 \mathrm{QR})$; the dots represent outliers for each distribution.

had received the COVID-19 vaccine. 999 Given the increased risk for COVID-19-related morbidity and mortality among older adults, addressing COVID-19 vaccine access barriers for socially vulnerable communities of older adults is critical. Among older adults, issues such as loneliness or absence of regular companionship (5), lack of computer or Internet literacy (6), and limited transportation options might be addressed through specialized outreach and vaccine distribution programs, as jurisdictions such as Miami, Florida, and Fulton County, Georgia, have demonstrated $(7,8)$. In some states, such as Texas and Pennsylvania, state health departments and vaccination providers have formed partnerships with interest groups and community-based organizations to create programs

\footnotetext{
$999 \mathrm{https://www.cdc.gov} / \mathrm{mmwr} /$ volumes/70/wr/mm7012e1.htm?s_ cid = mm7012e1_w; https://www.cdc.gov/nchs/products/databriefs/db370.htm
}

designed to guide older adults through the vaccination sign-up process and transport them to vaccination sites $(9,10)$.

The findings in this report are subject to at least five limitations. First, persons who were vaccinated through the Pharmacy Partnership for Long-Term Care Program**** were not analyzed separately. These persons, whose vaccinations were arranged and administered by pharmacy partners at their residential facilities, might not face access barriers similar to those experienced by persons in other residential settings. However, an estimated $95 \%$ of Medicare beneficiaries (who constitute an estimated $96 \%$ of older adults) reside in the community rather than long-term care facilities. ${ }^{\dagger \dagger \dagger \dagger}$ Second, associations between

\footnotetext{
**** https://www.cdc.gov/vaccines/covid-19/long-term-care/pharmacypartnerships.html

$+\dagger_{\dagger \dagger}$ https://www.agingstats.gov/docs/LatestReport/OA20_EmbargoCopy.pdf
} 


\section{Summary}

What is already known about this topic?

Older adults have experienced higher risk for

COVID-19-associated morbidity and mortality and therefore have been prioritized for COVID-19 vaccination.

What is added by this report?

After the first 3.5 months of the U.S. COVID-19 vaccination program, $79.1 \%$ of adults aged $\geq 65$ years had received $\geq 1$ dose, with higher vaccination initiation among men. Counties with lower vaccination initiation rates had higher percentages of older adults with social vulnerabilities.

What are the implications for public health practice?

Monitoring demographic and social factors affecting COVID-19 vaccine access for older adults and prioritizing efforts to ensure equitable access to COVID-19 vaccine are needed to ensure high coverage among this group.

county social vulnerability and vaccination initiation rates are ecological and reported for population-based indicators rather than individual-level vulnerability. Third, vulnerabilities and vaccination initiation rates might vary within counties because state and local jurisdictions might prioritize vaccination efforts for communities of older adults in smaller geographic units (e.g., ZIP codes). Fourth, older adult health and health care access are associated with numerous additional indicators for which recent data at the county level are not available. These additional indicators, such as living in multigenerational households or limitations accessing public transportation, might be associated with unexplained variance in the models. Finally, given that vaccine administration data are reported to CDC by multiple entities using various data systems, the possibility of underreporting, and thus, underestimation of vaccination coverage cannot be ruled out.

As COVID-19 vaccine supply expands along with the individual eligibility criteria, state and local jurisdictions can continue to ensure that older adults have equitable access to COVID-19 vaccines, including assistance with scheduling vaccination appointments and transportation to vaccination sites, or vaccination at home if needed for persons who are homebound. Assistance to ensure that persons receiving a vaccine that requires 2 doses to complete the series might be needed as well. Public health officials should continue to monitor vaccination initiation rates in the context of socioeconomic and demographic vulnerability to promote vaccine administration among this population at high risk for severe illness and death from COVID-19.

\section{Acknowledgment}

Monitoring and Assessment Team of the CDC COVID-19 Response's Vaccine Task Force.

Corresponding author: Ari Whiteman, osa0@cdc.gov.

${ }^{1}$ CDC COVID-19 Response Team; ${ }^{2}$ Geospatial Research, Analysis, and Services Program, Agency for Toxic Substances and Disease Registry, Atlanta, Georgia.

All authors have completed and submitted the International Committee of Medical Journal Editors form for disclosure of potential conflicts of interest. No potential conflicts of interest were disclosed.

\section{References}

1. Wortham JM, Lee JT, Althomsons S, et al. Characteristics of persons who died with COVID-19-United States, February 12-May 18, 2020. MMWR Morb Mortal Wkly Rep 2020;69:923-9. PMID:32673298 https://doi.org/10.15585/mmwr.mm6928e1

2. CDC. COVID-19 vaccination program interim playbook for jurisdiction operation. Atlanta, GA: US Department of Health and Human Services, CDC; 2021. https://www.cdc.gov/vaccines/imz-managers/downloads/ COVID-19-Vaccination-Program-Interim_Playbook.pdf

3. Lepkowsky CM, Arndt S. The internet: barrier to health care for older adults? Pract Innov (Wash D C) 2019;4:124-32. https://doi. org/10.1037/pri0000089

4. Jain A, van Hoek AJ, Boccia D, Thomas SL. Lower vaccine uptake amongst older individuals living alone: a systematic review and metaanalysis of social determinants of vaccine uptake. Vaccine 2017;35:2315-28. PMID:28343775 https://doi.org/10.1016/j. vaccine.2017.03.013

5. Wu B. Social isolation and loneliness among older adults in the context of COVID-19: a global challenge. Glob Health Res Policy 2020;5:27. PMID:32514427 https://doi.org/10.1186/s41256-020-00154-3

6. Hunsaker A, Hargittai E. A review of internet use among older adults. New Media Soc 2018;20:3937-54. https://doi. org/10.1177\%2F1461444818787348

7. City of Miami. City launches in-home COVID-19 testing service for homebound seniors. Miami, FL: City of Miami; 2021. https://www. $\mathrm{m}$ i a m i g o v. com/ $\mathrm{Not}$ i c e s/ $\mathrm{Nec}$ e $-\mathrm{M}$ ed i a / City-Launches-In-Home-COVID-19-Testing-Service-for-HomeboundSeniors

8. Fulton County. Senior transportation to vaccine appointments. Atlanta, GA: Fulton County; 2021. https://fultoncountyga.gov/news/2021/03/16/ senior-transportation-to-vaccine-appointments

9. Office of the Texas Governor. Governor Abbott announces "Save Our Seniors" initiative to vaccinate homebound seniors in Texas. Austin, TX: Office of the Texas Governor; 2021. https:/gov.texas.gov/news/post/ governor-abbott-announces-save-our-seniors-initiative-to-vaccinatehomebound-seniors-in-texas

10. Pennsylvania Department of Health. Wolf administration discusses partnership between COVID-19 vaccine providers, area agencies on aging, MCOs to help seniors secure vaccine appointments. York, PA: Pennsylvania Department of Health; 2021. https://www.media.pa.gov/ Pages/Health-Details.aspx?newsid $=1365$ 